\title{
SURFACE GEOMETRIC STRUCTURES OF CU DEPOSITED UPON $\alpha-\mathrm{Al}_{2} \mathrm{O}_{3}(0001)^{*}$
}

\author{
Q. Guo', P.J. MøLLER
}

Laboratory of Physical Chemistry, H.C. Ørsted Institute, University of Copenhagen 2100 Copenhagen, Denmark

AND L. GuI

Institute of Physical Chemistry, Peking University, Beijing, P.R. China

(Received February 13, 1992; revised version May 4, 1992)

\begin{abstract}
Upon deposition of $\mathrm{Cu}$ on a $1 \times 1 \alpha-\mathrm{Al}_{2} \mathrm{O}_{3}(0001)$ surface at room temperature the surface structure was found to change with increasing amounts of $\mathrm{Cu}$ deposited, from two-dimensional monolayer islands through three-dimensional nuclei until reaching a thin film. Subsequent surface heat-treatment to $650^{\circ} \mathrm{C}$ produced a stable $\mathrm{Cu}(111)-\mathrm{R} 30^{\circ}$ superstructure as observed by LEED.
\end{abstract}

PACS numbers: $68.65 .+\mathrm{g}, 68.55 . \mathrm{Bd}$

\section{Introduction}

The growth of copper upon alumina is of interest [1-3] due to its role as a catalyst in petrochemical processes. Studies by electron microscopy disagree $[4,5]$ as to whether or not a $\mathrm{Cu}(111)$ structure grows parallel to a sapphire $\alpha-\mathrm{Al}_{2} \mathrm{O}_{3}(0001)$ at high temperatures $\left(900-1080^{\circ} \mathrm{C}\right)$.

In the previous work we have reported $[6,7]$ results on the development of the surface electronic structures and on the thermal stability of deposits of copper onto $\alpha-\mathrm{Al}_{2} \mathrm{O}_{3}(0001)$ surfaces. In the present paper we report on further Auger electron spectroscopy (AES) and low-energy electron diffraction (LEED) studies on the surface geometric structure of $\mathrm{Cu}$ deposited on this substrate.

*This work was supported in part through Center for Surface Reactions and was presented at the 15th International Seminar on Surface Physics, Przesieka (Poland) 1991.

tOn lea ve from Institute of Physical Chemistry, Peking University. 


\section{Experimental procedures}

The experiments were carried out in a previously described [8] ultra-high vacuum system at pressures below $10^{-9}$ mbar. A single-pass cylindrical mirror analyzer was used for AES and 4-grid optics for LEED observation. The purity of the copper was $99.995 \%$ and the rates of $\mathrm{Cu}$ deposition were 1-3 $\AA \mathrm{min}^{-1}$. The thickness of the deposited copper layers was monitored by a quartz crystal microbalance. A new high-temperature method of pretreatment of the sapphire was used, as previously described [6]. An atomic-level clean surface was then obtained.

Strong charging effects are occurring within a certain primary energy range for metal oxide insulators [9]. For the present substrate the LEED patterns cannot be seen at primary energies below $60 \mathrm{eV}$, and the surface-charging increased with the amount of deposited copper as also seen for the $\mathrm{Cu} / \mathrm{MgO}$ system [9]. For temporary removal of the surface-charge disturbance a higher primary energy, 1-2 keV, was applied for a few seconds prior to photography. All Auger spectra and LEED patterns were recorded at room temperature.

\section{Results and discussion}

Figure 1 shows an ideal atomic arrangement from a (0001) sapphire surface with a hexagonal unit cell. The outermost layer consists of aluminum atoms, the second layer of oxygen and the third layer is again $\mathrm{Al}$, but in a position off from that of the outermost $\mathrm{Al}$ atoms. The corresponding LEED pattern from a clean

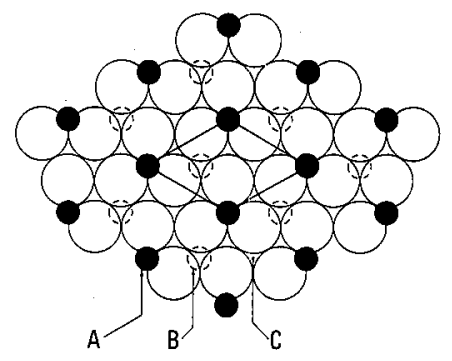

Fig. 1. $\alpha-\mathrm{Al}_{2} \mathrm{O}_{3}(0001)$ surface. Filled black circle: top layer (aluminum), large unfilled circle: second layer (oxygen), dashed circle: third layer (aluminum). A, B and C indicate different adsorption sites at the surface (see text). The unit cell is shown by bold lines.

$\alpha-\mathrm{Al}_{2} \mathrm{O}_{3}(0001)$ surface is a $1 \times 1$ structure; a hexagonal symmetry is seen.

Very small amounts of deposited copper, at average layer thicknesses $d_{\mathrm{Cu}}<$ $2 \AA$ deposited on the sapphire surface at room temperature, cause an increase in the background intensity from the substrate LEED pattern, and no new pattern was formed.

During the experiments it was observed that the surface charging increased with $d_{\mathrm{Cu}}$. Within the 2-10 $\AA$ range no LEED pattern could be obtained at primary beam energies below approximately $140 \mathrm{eV}$ because of strong charging effects. For 
thick layer deposits LEED patterns could not be obtained even at higher primary beam energies.

Heating samples with deposits in the $50-130 \AA$ range on the substrate to temperatures within the $110-650^{\circ} \mathrm{C}$ range results in a LEED pattern indicating a $\mathrm{Cu}(111) \mathrm{R} 30^{\circ} / 1 \times 1 \alpha-\mathrm{Al}_{2} \mathrm{O}_{3}(0001)$ surface structure as shown in Fig. 2.
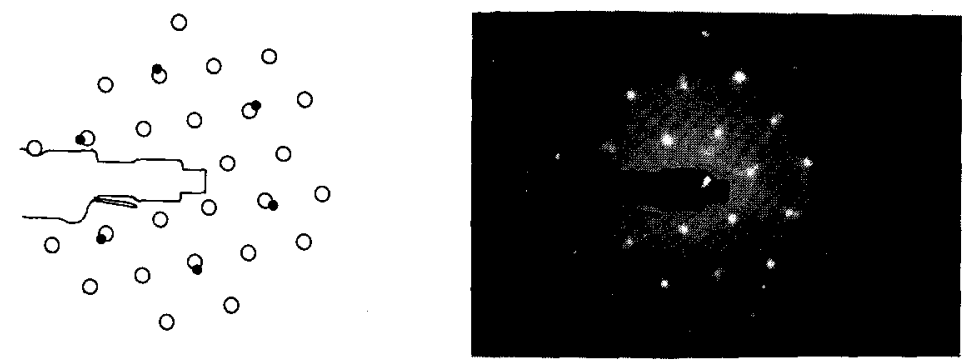

Fig. 2. LEED pattern from $\mathrm{Cu} / \alpha-\mathrm{Al}_{2} \mathrm{O}_{3}(0001)$ after an annealing at $650^{\circ} \mathrm{C}$ for $30 \mathrm{~min}$. Primary energy $164 \mathrm{eV}$, taken at room temperature. Full circles: sapphire substrate, filled circles: copper.

The AES measurements indicate that the Auger aluminum $(K L L)$-to-oxygen $(K L L)$ intensity ratio, $I_{\mathrm{Al}} / I_{\mathrm{O}}$, decreases during the initial $\mathrm{Cu}$ deposition, for $d_{\mathrm{Cu}}<$ $2 \AA$ in comparison to those of higher $\mathrm{Cu}$ coverages. Taking into account that the inelastic mean free path $\lambda$ in an $\mathrm{Al}_{2} \mathrm{O}_{3}$ film for $500 \mathrm{eV}$ electrons (i.e. $\mathrm{O}(K L L)$ ) is $\sim 10 \AA$ and that $\lambda \simeq 17 \AA$ for $1400 \mathrm{eV}$ electrons (i.e. $\mathrm{Al}(K L L)$ ), i.e. $\lambda_{\mathrm{Al}}>\lambda_{\mathrm{O}}$ in these measurements [10], then the results may perhaps indicate that the $\mathrm{Cu}$ atoms are positioned preferably at the top of aluminum sites, the A or B sites in Fig. 1 (and probably also at the $C$ sites, see Fig. 1), during the initial stages of the copper depositions, resulting in a decrease in the $I_{\mathrm{Al}} / I_{\mathrm{O}}$ AES intensity ratio.

The surface structure of the $\mathrm{Cu} / \alpha-\mathrm{Al}_{2} \mathrm{O}_{3}(0001)$ depends strongly on the cleanness of the substrate, and contaminants should be carefully removed, as controlled by AES.

Ideally, the outermost atoms of the $1 \times 1 \alpha-\mathrm{Al}_{2} \mathrm{O}_{3}(0001)$ surface are aluminum (see Fig. 1), but here the outermost atoms are expected to be oxygen due to the high-temperature oxidation pretreatment of the sample. This was confirmed by the measurement of the $I_{\mathrm{O}} / I_{\mathrm{Al}}$ intensity ratio. Thus, based upon the LEED and AES results we propose the surface structure of $\mathrm{Cu} / \mathrm{Al}_{2} \mathrm{O}_{3}(0001)$ for coverages $50 \AA<d_{\mathrm{Cu}}<130 \AA$ after heat-treatment to $650^{\circ} \mathrm{C}$ to be as modelled in Fig. 4 . The $\mathrm{Cu}-\mathrm{Cu}$ distance of $2.56 \AA$ of the $\mathrm{Cu}(111)$ plane was used in Figs. 3-4.

In summary, the surface geometric structure of $\mathrm{Cu}$ upon $\alpha-\mathrm{Al}_{2} \mathrm{O}_{3}(0001)$ changes with $\mathrm{Cu}$ coverage. For $d_{\mathrm{Cu}}<2 \AA$, islands, i.e. two-dimensional clusters (see Fig. 4a), are formed. The copper islands are not uniformly dispersed over the surface at this stage, therefore no superstructure is formed. At increasing coverages, $2 \AA<d_{\mathrm{Cu}}<50 \AA$, 3-dimensional clusters are formed (Fig. $4 \mathrm{~b}$ ). In this range, and particularly for $2 \AA<d_{\mathrm{Cu}}<20 \AA$, no LEED pattern could be obtained due to charging effects. Further deposition at room temperature results in full coverage 


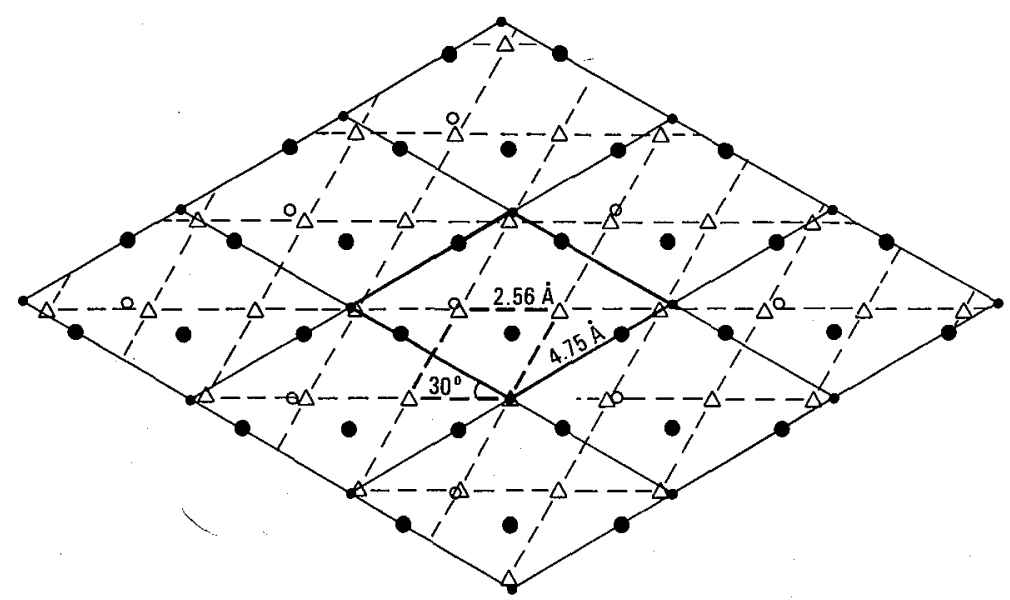

Fig. 3. Surface geometric structure of $\mathrm{Cu} / \mathrm{Al}_{2} \mathrm{O}_{3}(0001)$ after annealing for $30 \mathrm{~min}$ at $650^{\circ} \mathrm{C}$ for layer thicknesses within the 50-130 $\AA$ range. The lines show the unit cells for $\mathrm{Cu}(111)$ (dashed lines) and $\alpha-\mathrm{Al}_{2} \mathrm{O}_{3}(0001)$ (full lines), respectively.

a.

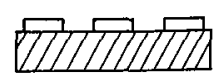

c.

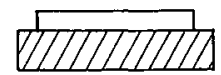

b.

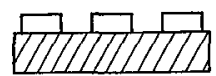

d.

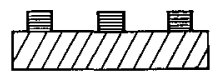

$$
\begin{aligned}
& \text { EUt } \alpha-\mathrm{Al}_{2} \mathrm{O}_{3} \\
& \square \quad \mathrm{Cu} \\
& \text { Cu (111) }
\end{aligned}
$$

Fig. 4. Schematic diagram of surface structure for $\mathrm{Cu}$ deposited on $\alpha-\mathrm{Al}_{2} \mathrm{O}_{3}(0001)$. (a) 2-D islands (room temperature, $d_{\mathrm{Cu}}<2 \AA$ ), (b) 3-D cluster (room temperature, $2 \AA$ $<d_{\mathrm{Cu}}<50 \AA$ ), (c) whole substrate covered by $\mathrm{Cu}$ (room temperature, $d_{\mathrm{Cu}}>50 \AA$ ), (d) $\mathrm{Cu}(111) / \alpha-\mathrm{Al}_{2} \mathrm{O}_{3}(0001)$ after annealing to $650^{\circ} \mathrm{C}$.

of the substrate (Fig. 4c). Heating the 50-130 $\AA$ deposited samples to $110-650^{\circ} \mathrm{C}$ for 10-30 min results in $\mathrm{Cu}$ agglomeration and formation of $\mathrm{Cu}(111)$ oriented nucleation centers, leading to a $\mathrm{Cu}(111) \mathrm{R} 30^{\circ} / \alpha-\mathrm{Al}_{2} \mathrm{O}_{3}(0001)$ surface structure (Fig. 4d) as observed by LEED.

\section{References}

[1] A.J. Pedraza, M.J. Godbole, D.H. Lowndes, J.R. Thompson Jr., J. Mater. Sci. 24, 115 (1989).

[2] E. Abonneau, G. Fuchs, M. Treilleux, A. Perez, Nucl. Instr. Methods B 46, 111 (1990). 
Surface Geometric Structures of Cu Deposited upon $\alpha-A_{2} O_{3}(0001) 651$

[3] J.E.E. Baglin, A.G. Schrott, R.D. Thompson, K.N. Tu, A. Segmüller, Nucl. Instr. Methods $B$ 19/20, 782 (1987).

[4] S.T. Lin, P.D. Ownby, J. Mater. Sci. 23, 3187 (1988).

[5] G. Katz, Thin Solid Films 33, 99 (1976).

[6] Q.L. Guo, P.J. Møller, Surf. Sci. 244, 228 (1991).

[7] Q.L. Guo, P.J. Møller, Vacuum 41, 1114 (1990).

[8] P.J. Møller, J.-W. He, J. Vac. Sci. Technol. A 5, 996 (1987).

[9] P.J. Møller, J.-W. He, Nucl. Instrum. Methods B 17, 137 (1986).

[10] F.L. Battye, J.G. Jenkin, J. Liesegang, R.C.G. Leckey, Phys. Rev. B 9, 2887 (1974). 